\title{
Preeklampsiye Sekonder Posterior Reversible Ensefalopati Sendromu (PRES): Olgu Sunumu
}

\author{
Preeclampsia Secondary Posterior Reversible Encephalopathy Syndrome (PRES): Case Report

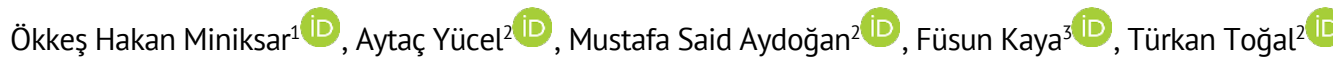 \\ 1 Anesteziyoloji ve Reanimasyon Ana Bilim Dalı, Yozgat Bozok Üniversitesi Tıp Fakültesi, Yozgat /Türkiye \\ 2 Anesteziyoloji ve Reanimasyon Ana Bilim Dalı, İnönü Üniversitesi Tıp Fakültesi, Malatya/Türkiye \\ 3 Anesteziyoloji ve Reanimasyon Bölümü, Kahramanmaraş Şehir Hastanesi, Kahramanmaraş/Türkiye
}

\section{ÖzeT}

Posterior Reversible Ensefalopati Sendromu (PRES) baş ağrısı, değişken mental bozukluk, epilepsi ve görme bozukluğu ile karakterize olup sıklıkla ani olarak yükselen ve kompanse edilemeyen arter basıncına bağlı olarak gelişir ve tanı klinik ve radyolojik olarak konulur. Illk olarak 1996 yılında Lökoansefalopati şeklinde tanımlanmıştır. Fakat bu hastalarda beyaz cevher ile birlikte gri cevher tutulumunun da olması nedeniyle günümüzde PRES terimi kullanılmaktadır. PRES'in erken teşhisi ve tedavisi oldukça önemlidir. Aksi takdirde kalıcı beyin hasarına ve kronik epilepsi gibi nörolojik sekellere neden olabilir. Bu makalede, preeklampsi ön tanısı olan 36 haftalık bir gebede postpartum dönemde klinik ve nöroradyolojik bulguları ile PRES tanısı konulan olgu sunulmaktadır.

Anahtar Kelimeler: posterior reversible ensefalopati sendromu, gebelik, preeklampsi

\section{ABSTRACT}

Posterior reversible encephalopathy syndrome (PRES) is characterized by headache, variable mental dysfunction, seizures, and visual loss and usually develops due to acutely increasing and uncontrollable arterial blood pressure, and it is diagnosed by clinic examination and radiologic imaging. Posterior reversible leukoencephalopathy has been recognized firstly in 1996 but influenced gray and white substances exist in brain 'PRES' word is used currently. Early diagnosis and treatment of PRES is very important. If it is not recognized, neurologic sequels such as established cerebral damage and chronic epilepsy can occur. In this article, we present a clinical and neuroradiological findings and a case of PRES diagnosis in a pregnant postpartum period of 36 weeks with preeclampsia diagnosis.

Keywords: reversible posterior leukoencephalopathy syndrome, pregnancy, preeclampsia

\section{Giriş}

Posterior reversible ensefalopati sendromu (PRES) baş ağrısı, değişken mental durum, epilepsi, görme bozuklukları ve tipik olarak beynin oksipito parietal bölgesinde ödem (beyaz cevherde) ile karakterize klinik ve radyolojik bir sendromdur. Sendromun bilinen nedenleri arasında, hipertansif ensefalopati, preeklampsi, eklampsi, HELPP sendromu, nöbeti takip eden postpartum dönem, immünosüpresif ve sitotoksik ilaçlar, hipertansiyona sekonder böbrek yetmezliği, kollajen vasküler hastalıklar, masif kan transfüzyonu yer alır. PRES tanısı anamnez ve radyolojik inceleme ile konulur. Erken tanı klinik seyir açısından önemlidir. Bilgisayarlı tomografi (BT) ve manyetik rezonans görüntüleme (MRG)'de genellikle oksipital ve paryetal loblarda tipik olarak subkortikal beyaz cevherde, bazen de kortekste büyük oranda simetrik yerleşimli ödemle karşımıza çıkar. PRES'in erken teşhisi ve tedavisi oldukça önemlidir. Aksi takdirde kalıcı beyin hasarına ve kronik epilepsi gibi nörolojik sekellere neden olabilir.

Bu olgu sunumunda, 36 haftalık preeklampsi ön tanılı bir gebede postpartum dönemde geçirdiği nöbet sonrası klinik ve nöroradyolojik bulguları ile PRES tanısı konulan vakanın sunulması amaçlanmıştır.

OLGU

34 yaşında, preeklampsi ön tanılı, 2 gebelik, 1 doğum öyküsü olan hasta, Kadın Hastalıkları ve Doğum Kliniği'nce spinal anestezi ile acil sezaryen operasyonuna alındı. Canlı ve sağıklı 3600 gr bebek doğurtuldu. İntraoperatif kan basıncı yüksek seyreden hasta, yakın takip amaçlı anestezi yoğun bakım ünitesine alındı. Yoğun bakım ünitesinde takiplerinde preoperatif olan tansiyon yüksekliği devam ett.

Yazışma Adresi/Address for Correspondence: Ökkeş Hakan Miniksar, MD, Yozgat Bozok Üniversitesi Tıp Fakültesi, Anesteziyoloji ve Reanimasyon Anabilim Dalı Yozgat /Türkiye

E-Posta/E-Mail: hminiksar@yahoo.com || Tel: +90 5304686718

Received/Geliş Tarihi: 28 Nis 2019 || Accepted/Kabul Tarihi: 04 Kas 2019

Bu Eser Creative Commons Atıf-Gayriticari 4.0 Uluslararası Lisansı İle Lisanslanmıştır. This work is licensed under a Creative Commons

Attribution-NonCommercial 4.0 International License (CC BY-NC 4.0). 
Arteriyel kan basıncının 210/115 mmHg olarak saptanması üzerine nitrogliserin $0,25 \mu \mathrm{g} / \mathrm{kg} / \mathrm{dk}$. infüzyonu başlanıldı. Takiplerinde tedaviye rağmen hipertansif seyreden hastada 10. saatte ani bilinç kaybı ve jeneralize tonik klonik nöbet gelişti. Midazolam uygulandı ve solunumu yüzeyelleşen hasta mekanik ventilasyona bağlandı. Hastaya intraarteriyel kanülasyon uygulandı. Arteriyel kan basıncı ve laboratuvar parametreleri yakından takip edildi. Preoperatif dönemde başlanan intra venöz (IV) magnezyum sülfat (MgSO4) tedavisine 24 saat devam edildi. Analjezik tedavisine rağmen devam eden refrakter hipertansiyon için, kombine antihipertansif tedavi olarak, oral alfa-metil dopa günde 3 kez $250 \mathrm{mg}$ tablet ve amlodipine $5 \mathrm{mg} /$ gün eklendi ayrıca intravenöz esmolol infüzyonu başlandı. Nöroloji konsültasyonu yapılan hastaya antiepileptik tedavi amacıyla sodyum valproat $2 \times 400 \mathrm{mg}$ başlandı. Kraniyal bilgisayarlı tomografi (BT)'de, bilateral pariyeto-oksipital loblarda ve frontal bölgelerde beyaz ve gri cevherde lokalize olmak üzere simetrik hipodens alanlar tespit edildi. Ayırıcı tanı amaçlı çekilen kraniyal difüzyon MRG'de ise bilateral frontooksipital bölgede kortekse uzanım gösteren multipl vazojenik ödem saptandı ve bu görünüm radyoloji kliniği tarafından PRES ile uyumlu görünüm olarak değerlendirildi (Resim 1). Laboratuvar incelemesinde üre:18 mg/dl, kreatinin:0,74 mg/dl, $\mathrm{Na}: 138 \mathrm{mmol} / \mathrm{L}, \quad \mathrm{K}: 4,8 \mathrm{mmol} / \mathrm{L}$, T.Ca:8,28 mg/dl, Hb:10,7 g/dl, beyaz küre:13,6 K/uL, trombosit sayımı:53.000/mm3, AST:797 IU/ L , ALT:258 IU/ L, total bilirubin:3,22 $\mathrm{mg} / \mathrm{dl}$ direk bilirubin:1,15 mg/dl, LDH:3898 IU/ L, albumin:1,7 gr/dl ve fibrinojen:144 mg/dl, PTZ 10.7 sn, aPTT 37.7 sn, INR:0.9 idi. Hastaya metilprednizolon $1 \mathrm{mg} / \mathrm{kg}$, insan albümini $2 \times 1$, 1 adet trombosit aferezi, 1 gr fibrinojen çözeltisi uygulandı. Hasta hematoloji bölümüne konsülte edildi. Periferik yaymada (PY) anizositoz, poikilositoz, \%2-3 fragmente eritrositler, yer yer tekli ikili trombositler; $\% 88$ nötrofil, $\% 8$ monosit ve $\% 4$ lenfosit saptandı. PY bulguları HELLP Sendromu ile uyumlu olduğu belirtildi. Hematoloji bölümü önerileri ile gün aşırı plazmaferez uygulandı. Takiplerinde bilateral plevral efüzyon gelişen hasta Göğüs Cerrahi tarafından değerlendirildi ve girişimsel işlem önerilmedi. Hemodinamisi ve laboratuvar bulguları stabil seyretmeyen hasta sedatize ve mekanik ventilatöre bağlı olarak takip edildi. Hematoloji bölüm önerisi ile 5. gün kontrol PY, LDH, AST, ALT, PLT değerlerinin normal görülmesi üzerine plazmaferez sonlandırıldı ve sedasyonu kesildi. Bilinci açılan hasta ekstübe edilerek maske oksijen ile takip edildi. Hemodinamisi stabil seyreden ve nörolojik sorunları tam olarak düzelen hasta, yatışının 10. Günü, oral antihipertansif ve antiepileptik tedavileri düzenlenerek kadın doğum servisine nakledildi. Olgumuzun 3 aylık takibi sonucunda, sık tansiyon takibi yapıldığı ve herhangi bir nörolojik sekel olmadığı öğrenildi.

Resim 1. Kranial Difüzyon $M R G$, bilateral fronto-oksipital bölgede kortekse uzanım gösteren multipl vazojenik ödem (PRES ile uyum/u).

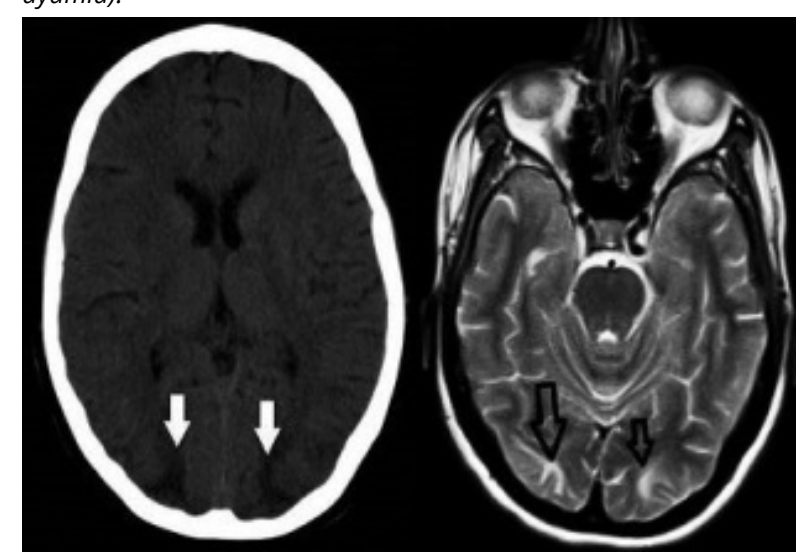

\section{TARTIŞMA}

Bu olgu sunumunda, preeklampsi ön tanısı olan gebe hastada postpartum dönemde hayatı tehdit eden ve yoğun bakımda yakın takip gerektiren PRES tablosu sunulmuştur. PRES birçok karmaşık mekanizmanın neden olduğu, tipik beyin görüntüleme bulgularının eşlik ettiği; bulantı, kusma, bilinç değişikliği, baş ağrısı, görme bozuklukları, nöbet geçirme, fokal nörolojik bulgular ile karşımıza çıkabilen nörotoksik bir klinik durumdur. Etiyopatogenezi tam olarak ortaya konulamamıştır. Literatürde hipertansif ensefalopati, preeklampsi, eklampsi, otoimmün hastalıklar , enfeksiyon, sepsis, septik şok ve kemoterapi sonrası geliştiği bildirilmiştir. Sitotoksik zeminde gelişen serebral vazojenik ödem suçlanmıştır (1). Bizim hastamızda etiyolojinin, preeklampsi ve eşlik eden eklampsi sonucu hipertansif ensefalopati olduğunu düşünmekteyiz. Ayırıcı tanıda anamnez, klinik bulgular ve görüntüleme teknikleri kullanılmalıdır. Ayırıcı tanı olarak PRES sendromu gözlenen gebelerde unutulmaması gereken ve semptomları karıştırılan en önemli klinik tablo, dural sinüs trombozudur (2). Bu sebeple dikkatli olunmalıdır. PRES ayırıcı tanısında bilateral posterior lob enfarktları, serebral venöz tromboz, serebral vaskülitik etkilenme, hipertansif ensefalopati, herpes virüs ansefalitleri, hipoglisemi ve hiponatremi düşünülmelidir. Ayırıcı tanıda hikaye, fizik muayene, 
laboratuvar bulguları, intravenöz kontrastlı nöroradyolojik inceleme ve serolojik testlerle bu tanılar ekarte edilmelidir (2).

PRES'in kesin mekanizmasını tam olarak anlaşılamamıştı; ancak kan-beyin bariyerinin bütünlüğünün bozulması ile ilgili olduğu düşünülmektedir. Hastamızda da mevcut olan Preeklampsi, hipertansiyon ve proteinürinin eşlik ettiği gebeliğe özgü bir sendromdur. Preeklampsinin patogenezinde vasküler yatakta spazm ve buna bağlı endotelyal disfonksiyon bulunmaktadır. $\mathrm{Bu}$ endotelyal disfonksiyon, PRES'de serebral patolojilerin açıklanmasında anahtar rol oynamaktadır. Bu tabloya hipertansiyonun eklenmesiyle beynin oto regülasyonu bozulur ve vazospazm meydana gelir. Bu da hücre düzeyinde iskemiyle sonuçlanır. İkinci teoride ise serebral oto regülasyon barajını aşan ani kan basıncı yüksekliklerinin, kapiller düzeyde hidrostatik basınç artışına yol açtığı kabul edilir. Bu da plazmanın ekstravazasyonuna ve vazojenik ödeme neden olur. PRES genellikle gebeliğin 28. haftası ile postpartum 13. gün arasındaki dönemde ortaya çıkmaktadır (3). Hastamızda PRES tablosu postoperatif 1. günde gelişti. Klinik olarak şiddetli hipertansiyon yanında, baş ağrısı sonrasında bilinç kaybı ve konvülziyon vardı. Hastaya mekanik ventilasyon desteği sağlandıktan sonra akut serebrovasküler olayın ekarte edilebilmesi ve hipertansif ensefalopatiye bağlı olası PRES sendromu tanısı için öncelikle beyin BT sonrasında beyin MR görüntüleme yapıldı ve PRES ile uyumlu bilateral fronto-oksipital loblarda belirgin olmakla birlikte yaygın serebral ödem görüldü. PRES'in tanısında görüntüleme yöntemlerinden en çok difüzyon MRG faydalıdır. MRI'da T2 ağırlıklı görüntüler (T2A) ve FLAIR görüntülerde hiperintens, T1 ağırlıklı görüntülerde (T1A) hipointens karakterde posterior serebral dolaşım alanına uyan parieto-oksipital bölgede bilateral ve simetrik yerleşimli multipl vazojenik ödem alanları görülür (4). Ancak, daha ciddi olgularda bu bulgular posterior frontal ve temporal loblarda, derin beyaz cevherde, ponsta, serebellumda ve diğer bölgelerde de görülebilmektedir (5). Bu olgularda, hastanın takip edildiği merkezde mevcut ise, bilgi verici özelliği fazla olan, difüzyon MR görüntülemesi yapılması önerilmektedir. PRES'teki ensefalopatiyi hipodens lezyonlar olarak gösteren bilgisayarlı tomografi (BT) de görüntülemede kullanılabilir (4).
Bu sendromun tedavisi temel olarak nedene yöneliktir. Erken dönemde tedavi başlanmazsa etkilenen beyin bölgelerinde hayatı tehdit eden hemorajiler gelişebilir. Hipertansiyon hastaların büyük çoğunluğunda semptomlara eşlik eder. Ortalama arteriyel kan basıncı ilk 1-2 saat içinde \%20-25 oranında azaltılmalıdır. Kan basıncı kontrol altına alınmalı, eğer gebelik toksikozu düşünülüyorsa sezaryen düşünülmeli, elektrolit bozuklukları ve metabolik bozukluklar düzeltilmeli, antiepileptik tedavi düzenlenmelidir (6). Hastamızda etiyolojinin postoperatif dönemde güç regüle edilebilen hipertansiyona bağlı ensefalopati olduğu düşünülüp çoklu antihipertansif tedavi başlanmıştır. Kafa içi basıncı artırabilecek durumlardan kaçınılmış ve antiepileptik tedavi başlanmıştır. Hipertansiyon tedavisinde intravenöz ve oral antihipertansif ajanlar, sedatif hipnotikler ve diüretikler kullanılabilir. İlginç olarak, PRES normotansif hastalarda ve sadece hafif kan basıncı yüksekliği olan hastalarda da gelişebilir. PRES gelişen hastaların \%20-30'unda kan basıncı toksisite esnasında normaldir. Bu durum daha çok eklampsi, kemik iliği nakli, siklosporin toksisitesi olgularında gözlenir (7).

MgSO4, eklampsi ve PRES'te kan-beyin bariyerini koruyarak ve serebral ödemi sınırlayarak antikonvülzan etkilidir. Ancak bazen PRES sendromu oluştuktan sonra nöbetlerin önlenmesinde MgSO4 yetersiz kalmaktadır (8). Bizim hastamızda da doğum öncesi dönemden itibaren $\mathrm{MgSO} 4$ tedavisi almakta iken postpartum dönemde gelişen konvülziyonlar sonrası tanı konulan PRES tablosu söz konusudur. Tedavide MgSO4'ın yetersiz kalma nedeni PRES sendromunda nöbetlerin serebral iskemik ve ödemli alanlara bağlı gelişmesidir. Tedaviye anti ödem ve antiepileptik ilaçlar eklenmesi gerekebilir (8). Olgudaki MgSO4 tedavisinin yetersiz kalma nedeni serebral iskemik ve ödemli alanlara bağlı olarak değerlendirilmiştir.

\section{SONUÇ}

Sonuç olarak preeklampsi/eklampsi ön tanısı olan gebelerde postpartum dönemde posterior reversible ensefalopati sendromu gelişebileceği akılda bulundurulmalıdır. PRES radyolojik ve klinik olarak geri dönüşümlü bir tanı olup erken tanı ve tedavi ile bu olgularda kalıcı sekellerin önüne geçilebileceğini düşünmekteyiz... 
Yazarlar arasında çıkar çatışması yoktur.

The author declares no conflict of interest.

Finansal Destek: yoktur / Funding : none

Bu olgu 'TARK 2014 Ulusal Kongresi'nde ( 25-29 Ekim 2014, Ankara) e-poster olarak sunulmuştur.

doi: ***************

\section{KAYNAKLAR}

1. Çalım $M$, Daşkaya $H$, İnal $F Y$, İdin $K$, Ölçülü $i H$, Salihoğlu $Z$. Life-Saving Intensive Care Unit in Cases of Posterior Reversible Encephalopathy Syndrome. Anatolian Clinic, January 2017;22:1. Doi: 10.21673/anadoluklin.252168

2. Teksam M, Casey SO, Michel E, Truwit CL. Posterior Reversibl Ensefalopati Sendromu: Patofizyoloji ve İleri MRG teknikleri ile korelas`yon. Tanısal ve Girişimsel Radyoloji. 2001;7:464-472.

3. Cunningham FG, Leveno KJ, Bloom SL. Pregnancy Hypertension. Williams Obstetrics. The Mc Grawhill Companies Inc. 23rd Ed. 2010:706-757.

4. Garg RK. Posterior leukoencephalopathy syndrome. Postgrad Med J. 2001 Jan;77:24-28.

5. Schwartz RB, Bravo SM, Klufas RA, Hsu L, Barnes PD, Robson $C D$ et al. Cyclosporine neurotoxicity and its relationship to hypertensive encephalopathy: CT and MR findings in 16 cases. AJR Am J Roentgenol. 1995;165:627-631. Doi: 10.2214/ajr.165.3.7645483

6. Legriel S, Pico F, Azoulay E. Understanding Posterior Reversible Encephalopathy Syndrome. Annual Update in Intensive Care and Emergency Medicine. 2011;1:631-653. Doi: 10.1007/978-3-642-18081-1_56

7. Stevens CJ, Heran MK. The many faces of posterior reversible encephalopathy syndrome. Br J Radiol. 2012;85:1566-1575. Doi: $10.1259 / \mathrm{bjr} / 25273221$

8. Demirtaş O, Gelal F, Vidinli BD, Demirtaş LO, Uluç E, Baloğlu A. Cranial MR imaging with clinical correlation in preeclampsia and eclampsia. Diagn Interv Radiol 2005;11(4):189-194... 